\title{
Daylight Quality in Healthcare Design, Daylight Measurements Results and Discussion, Case Study: Jordan University Hospital
}

\author{
Sahar Diab, Bayan Abu Qadourah and Riziq Hammad \\ Department of Architecture, Jordan University, Amman 11942, Jordan
}

Received: November 14, 2016 / Accepted: November 22, 2016/ Published: March 31, 2017.

\begin{abstract}
This study's purpose is to evaluate and analyse the indoor daylight quality in Pediatrics Ward in JUH (Jordan University Hospital). It conducts an investigative analysis associated with an evaluative approach for the daylight situation in patient rooms in the children section. A multi-method approach used including on-site measurements, and building model to develop a framework for lighting design in Paediatrics Ward, in order to determine whether the current quality meets the recommended values for patient rooms by CIBSE or not. The study considered the following variables: the differences in daylight environments (illuminance, luminance level, daylight factor), and the physical environment properties of patient rooms in the hospital. The study found that the indoor daylight performance in terms of illuminance, luminance level, and daylight factor in east patient rooms are higher than the recommended values by CIBSE in the area nearest to glass window at the morning and less than the recommended values in the depth of the room at afternoon. Therefore, solar reflective technologies and shading system must be provided for enhanced day lighting control, avoid excessive glare and to guarantee a good level of visual comfort for patients and staff while reducing artificial lighting demand.
\end{abstract}

Key words: JUH, indoor daylight, health care, CIBSE, control system of day lighting, energy consumption.

\section{Introduction}

Hospital environments present special challenges continuously during the running time of the hospitals. Several studies that are related to healthcare design showed dissatisfaction from hospital environment, such as comfort, lighting, IAQ (indoor air quality), temperature, humidity, and noise. Using daylight as primary light source has been widely recognized as an important strategy to reduce building energy demand and enhance indoor environment quality.

However, there is a lack of studies in Jordan that deal with architectural efforts to address the indoor daylight quality in hospitals. In fact, Jordan needs intensive research to address healthcare facility problems such as lighting in patient rooms, daylight level, and other necessary conditions for patients' satisfaction [1]. This

Corresponding author: Sahar Diab, M.Sc. in architectural engineering, architect, research field: building science. study attempts to cover research shortage in this field.

\subsection{Daylight in Hospitals}

The research suggests a strong association between health outcomes and the physical environment in which a person lives or receives treatment [2]. Light, especially daylight impacts on visual performance and psychological state of a person by regulating the circadian rhythm. It impacts on patient outcome, as well as provides restorative benefits to medical staff and office workers. After decades of research on the healthcare physical environment it is hard to ignore the fact that it has an impact on users [2]. The lack of daylight has also been associated with job burnout and medication errors [3, 24].

The argument that natural light is to be efficiently incorporated into lighting design in healthcare settings is not only because it benefits patients and staff, but also this type of light is delivered at no cost and it is in a 
form that generally all people prefer. Several studies have shown the importance of light in decreasing depression, reducing fatigue, improving alertness, modulating circadian rhythms, and treating conditions such as hyperbilirubinemia among infants [4].

Recommended lighting levels for patient rooms are 200-220 lux while ensuring at least four types of lights — general, reading, examination and night lighting [23] see Table 1.

Recent studies correlated the relationship of medication errors to lighting levels. As lighting intensity approaches 1,500 lux, the incidence of medication errors dramatically decreases. Poor lighting and lack of daylight are linked to depression, increased need for pain medication, medication errors, and order entry errors [5]. In the event of daylight, suitable solar control should be foreseen, to minimize problems with uneven light distribution and glare.

Visual discomfort caused by excessive daylight and glare can be prevented by installing proper shading devices, such as vertical or horizontal blinds. By using such a device, the high luminance ratio, diversity of illuminance, and illuminance level can be controlled and adjusted to the values recommended by CIBSE and IESNA [6].

Improving the quality of care and efficiency of service delivery while reducing costs has become increasingly important because of the pressures on budgetary in recent years. Healthcare expenditure accounts for a significant share of the national budget in most countries [11]. Jordan, as a developing country, has no significant oil resources with limited slow progress in energy sector, and natural gas reserve which is not able to support a substantial production increase. With the increase of electricity demand, and in parallel to the global tropism to renewable energy, and its different resources; solar, hydropower, wind, tide, geothermal, and the problem of climatic changes, its became a high challenge with Jordan's potential position to get benefit from the solar energy as one of the most important energy resources [12].
Table 1 Recommendation for a patient room (illuminance at floor level) (CIBSE2002).

\begin{tabular}{llll}
\hline & $\begin{array}{l}\text { Maintained } \\
\text { illuminance } \\
\text { (lux) }\end{array}$ & $\begin{array}{l}\text { Limiting glare } \\
\text { rating }\end{array}$ & $\begin{array}{l}\text { Minimum } \\
\text { color rendering } \\
\text { (Ra) }\end{array}$ \\
\hline $\begin{array}{l}\text { General } \\
\text { lighting }\end{array}$ & 100 & 19 & 80 \\
$\begin{array}{l}\text { Reading } \\
\text { lighting }\end{array}$ & 300 & 19 & 80 \\
$\begin{array}{l}\text { Simple } \\
\text { examinations }\end{array}$ & 300 & 19 & 80 \\
\hline
\end{tabular}

Reports assert that hospitals should be the most rigorous in implementing environmentally sustainable design practices and environmental stewardship [7-10]. Daylight is the primary, free and the most important light source for building's internal spaces during the daytime [13].

\subsection{Jordan University Hospital}

JUH (Jordan University Hospital) is located North West of the Capital Amman, within Jordan University Complex and surrounded by its beautiful gardens. The hospital consists of 7 storeys high-rise building, in which all hospital beds are located and 2 storeys of low-rise buildings in which outpatient clinics, diagnostic and other services are located. It has also a double storeys car parking with. Jordan University Hospital includes more than 25 specialized medical units; it has 64 specialty and subspecialty in the different medical fields, and a bed capacity of 550 .

The researchers chose JUH for many reasons; firstly, this hospital is located in a semiarid zone where the balance between daylight and thermal models performance in buildings is much needed. Secondly, JUH is the first university teaching hospital in Jordan.

The high-rise part has 2 parallel wings that are connected by intermediary structure. The Paediatrics Ward occupies the 7th floor in east wing (see Fig. 1). The patient rooms are located into east and west of the floor. All services room located in the middle of department, and the south and north part ended by outdoor terraces. The daylight conditions are different in each side. Half of the patient rooms are oriented east 


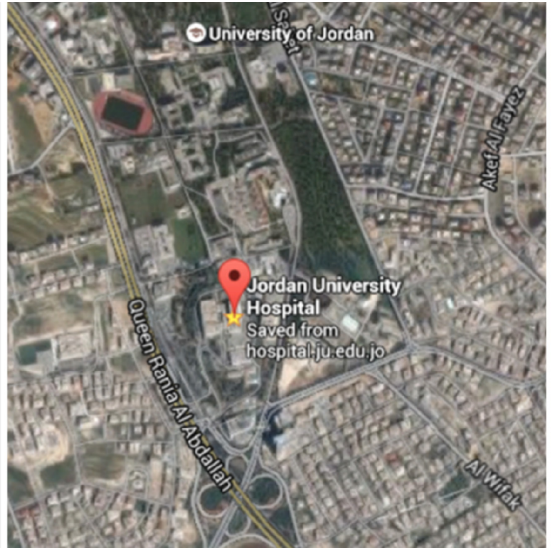

(a)

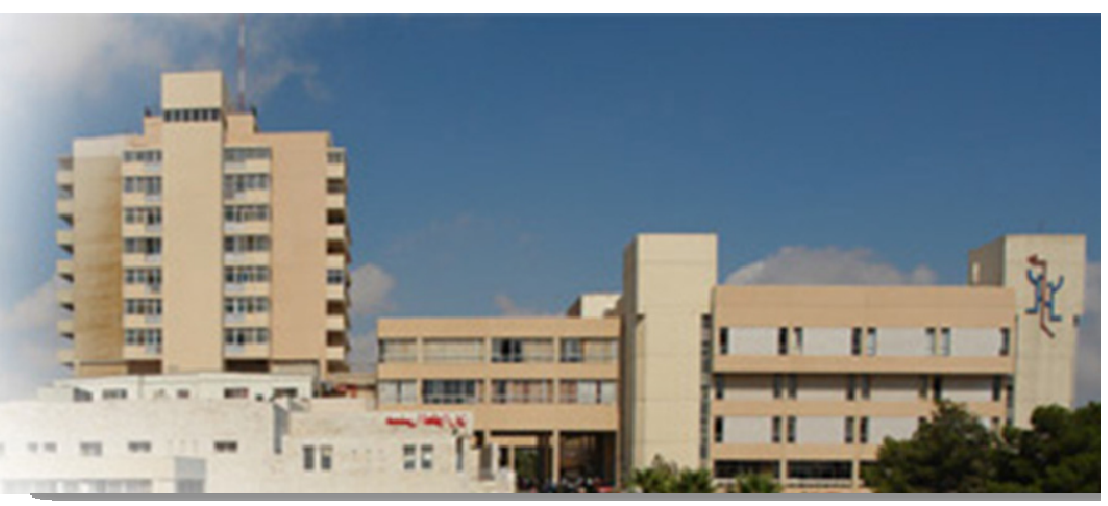

(b)

Fig. 1 Illustration for Jordan University Hospital: (a) The location of the hospital in Jordan (Google earth, 2015); (b) A daytime photo for hospital (http://hospital.ju.edu.jo/medical/juhospital/Home.as).

and the other half faces west. The patient rooms in JUH have two size one for 3 beds and another for 6 beds in each room. This research studies the east room which accommodates 6 beds.

\section{Methodology}

A multi-method approach used in this study, lab test and on-site measurements were conducted to investigate, analyse, and evaluate the daylight conditions in patient rooms in pediatric wards at JUH.

\subsection{On-site Measurements}

The room dimensions are $8 \times 7 \times 3.2 \mathrm{~m}$; it contains 6 beds, 2 windows located in east side. The internal illuminance levels in the patient rooms were measured using a grid of $1.5 \mathrm{~m}$ by $3.5 \mathrm{~m}$ at a height of $0.95 \mathrm{~m}$ above the floor finish at 6 points. Every point is located in the centre of each bed, turn off artificial lighting and open the blind.

The lux meter used to measure the internal illuminance levels in the patient room. The field measurement occurred on 13th, 17th and 21st of April. The average was taken to more accurate values as shown in Table 2. CAD (computer aided design) software was used to model the patient room configurations (see Fig. 2). D-plot analysis graphic was used as a tool to present the result as shown in Fig. 3.

\subsection{Analysis and Discussion}

Comparative analyses were conducted for the field measurements of the current situation, and the recommended values.

\subsubsection{Illuminance Level}

The recommended illuminance level in a patient room is 100 lux for general lighting and 300 lux for reading (CIBSE, 2002). The differences vary from 48 lux to 4,847 lux, which means that there are unequal lighting values in the whole room depending on the time and depth of each point in the room.

The average illuminance level exceeds 3,000 lux at the morning ( 9 am-12 pm) in points $1-4$, but in the same time the average illuminance level at points 5 and 6 is around 150 lux which reaches the recommended values. In the afternoon ( $1 \mathrm{pm}-5 \mathrm{pm})$ the average illuminance level at points 1 and 2 is around the 190 lux which is around the recommended values, for points $3,4,5$ and 6 at the same time the average illuminance level is around 90 lux in average which is under the recommended values.

The results show that the average illuminance level is more than recommended in the morning for nearest point and in the afternoon it is under than the recommended in the depth of the room. The east facing rooms in pediatric department have excessive 


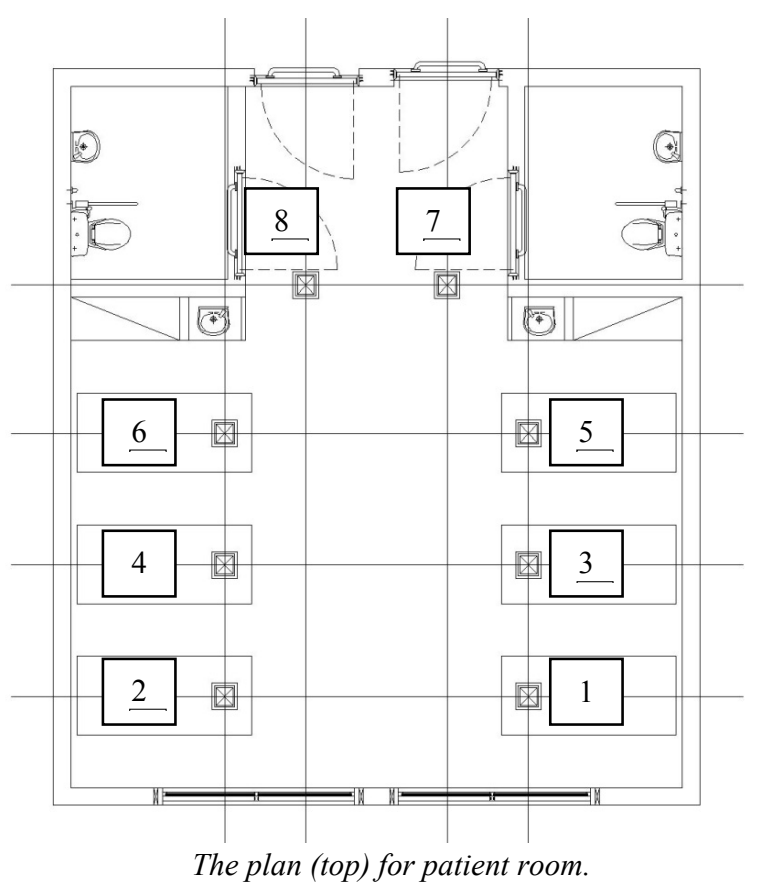

The plan (top) for patient room

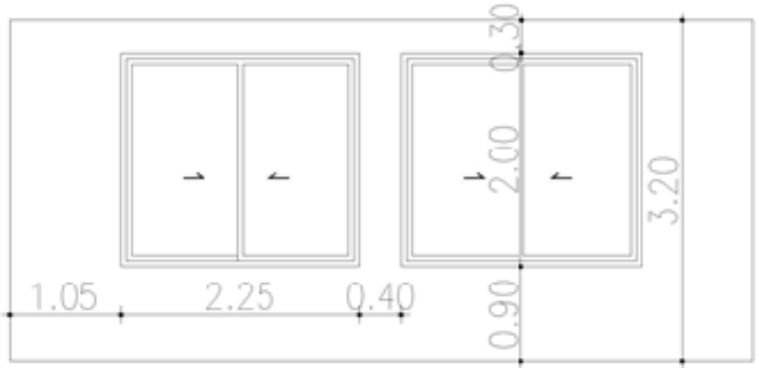

Interior elevation (bottom) for windows in patient room.

Fig. 2 Illustration for on-site measurements.

Table 2 The average of onsite measurements of 13th, 17th and 21st of April, 2015, the researchers. The Measurement hour at Amman timing is +3 GMT.

\begin{tabular}{|c|c|c|c|c|c|c|c|c|c|}
\hline Points No. & $\begin{array}{l}9 \mathrm{am} \\
\text { (lux) }\end{array}$ & $\begin{array}{l}10 \text { am } \\
\text { (lux) }\end{array}$ & $\begin{array}{l}11 \mathrm{am} \\
\text { (lux) }\end{array}$ & $\begin{array}{l}12 \mathrm{pm} \\
\text { (lux) }\end{array}$ & $\begin{array}{l}1 \mathrm{pm} \\
\text { (lux) }\end{array}$ & $\begin{array}{l}2 \mathrm{pm} \\
\text { (lux) }\end{array}$ & $\begin{array}{l}3 \mathrm{pm} \\
\text { (lux) }\end{array}$ & $\begin{array}{l}4 \mathrm{pm} \\
\text { (lux) }\end{array}$ & $\begin{array}{l}5 \mathrm{pm} \\
\text { (lux) }\end{array}$ \\
\hline 1 & 3,224 & 1,087 & 782 & 316 & 286 & 283 & 204 & 169 & 149 \\
\hline 2 & 4,847 & 982 & 1,071 & 307 & 309 & 311 & 223 & 209 & 171 \\
\hline 3 & 790 & 512 & 284 & 182 & 166 & 120 & 109 & 81 & 65 \\
\hline 4 & 514 & 412 & 243 & 176 & 164 & 114 & 88 & 83 & 77 \\
\hline 5 & 389 & 201 & 177 & 107 & 82 & 76 & 35 & 46 & 38 \\
\hline 6 & 321 & 180 & 160 & 113 & 75 & 70 & 61 & 50 & 48 \\
\hline
\end{tabular}

Time

9 am
2D analysis

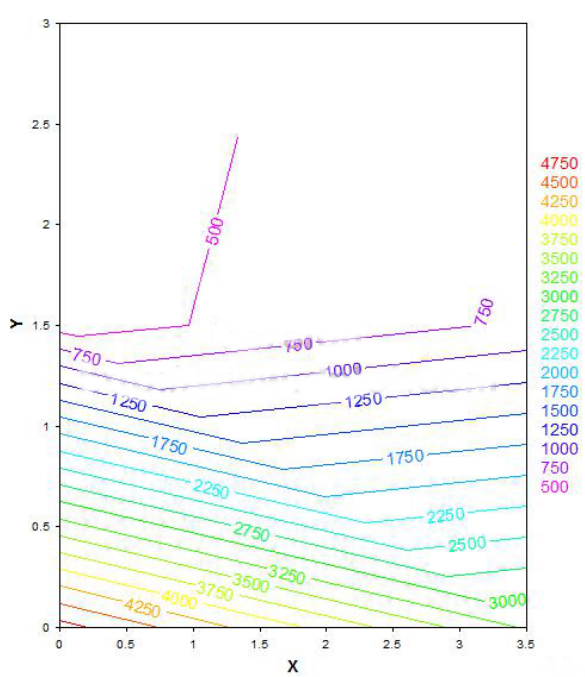

3D analysis

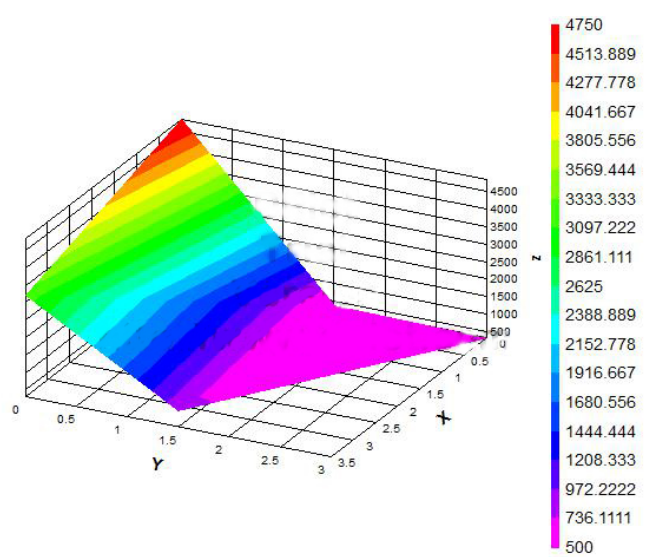


10 am
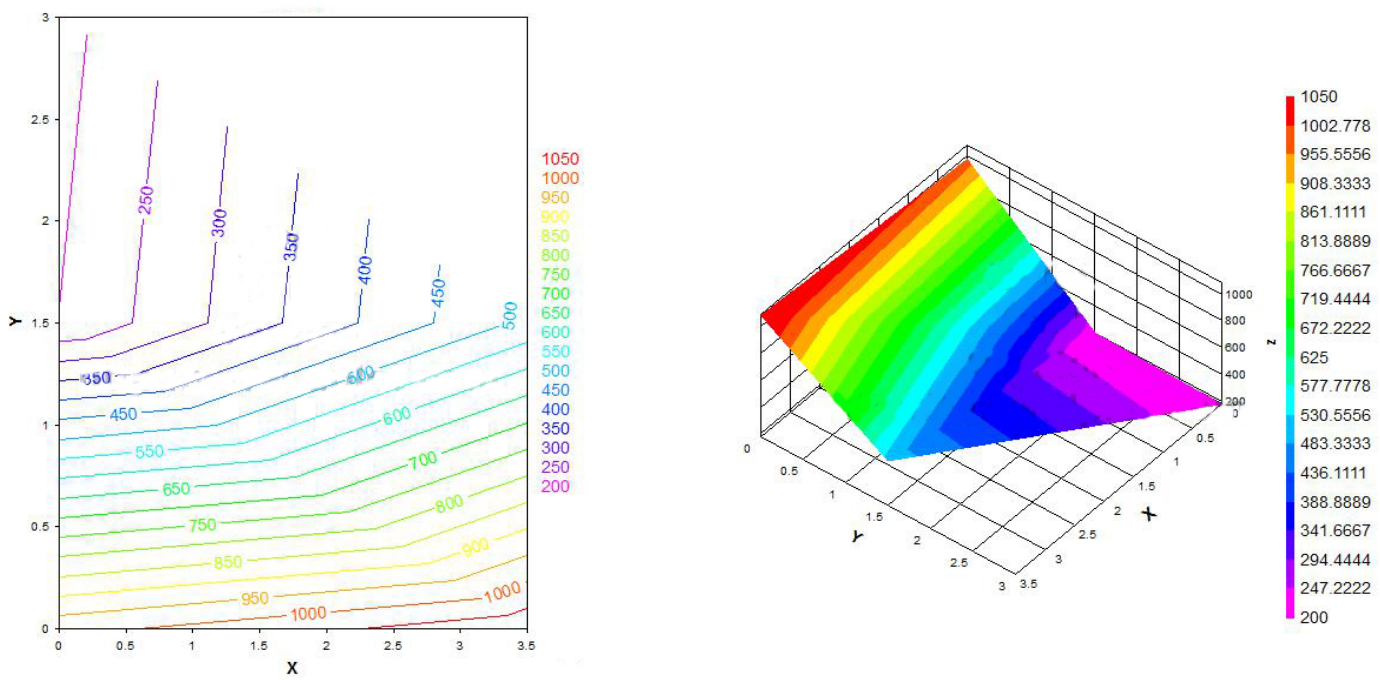

4 pm
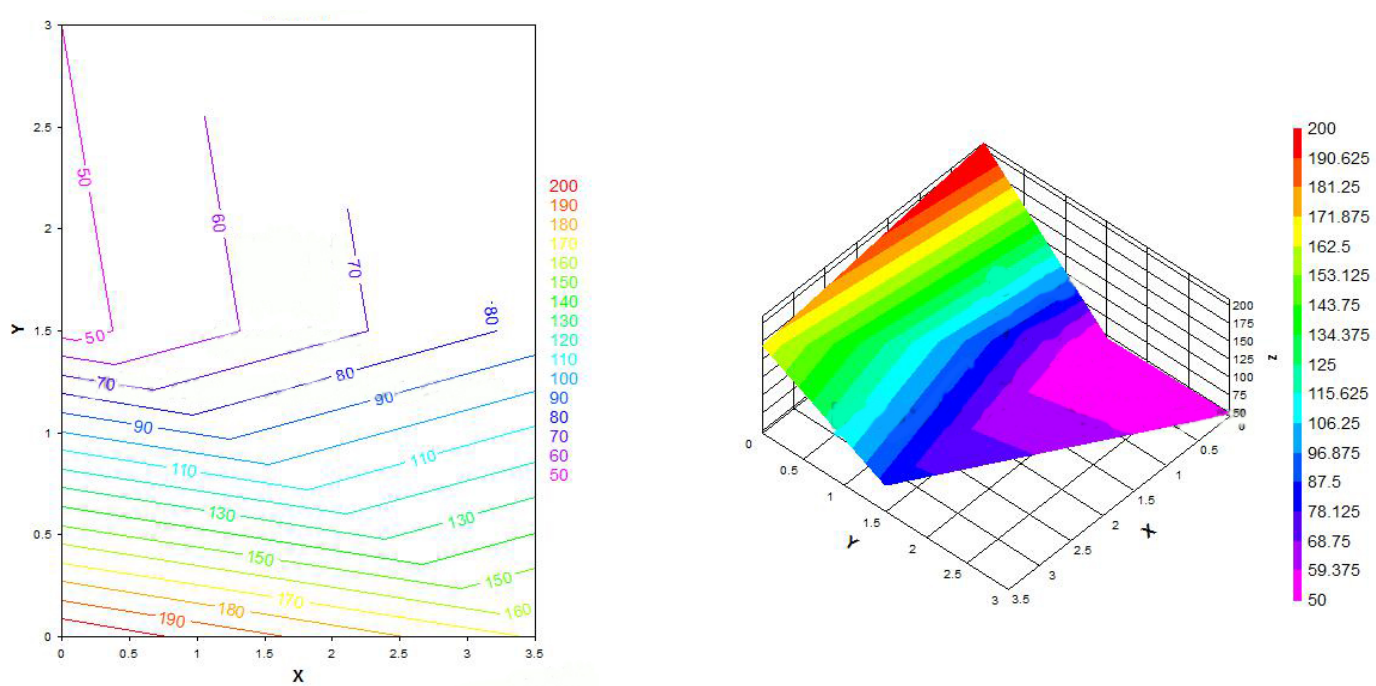

5 pm
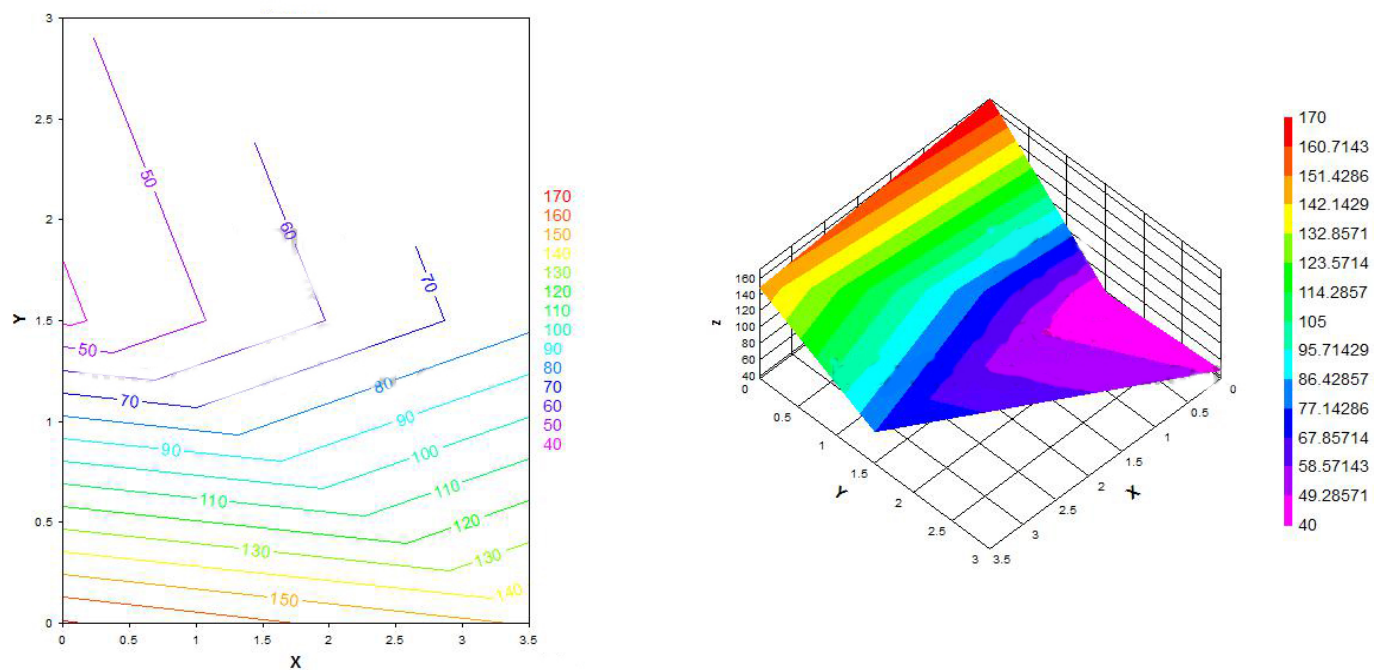

Fig. 3 D-plot analysis graphic presents the result of average illuminance level. Note: The measurement hour at Amman timing is +3 GMT. 
Table 3 DF values in the patient rooms. Note: the measurement hour at Amman timing is +3 GMT.

\begin{tabular}{|c|c|c|c|c|c|c|c|c|c|}
\hline $\begin{array}{l}\text { Points } \\
\text { No. } \\
\end{array}$ & $\begin{array}{l}9 \mathrm{am} \\
\text { (lux) }\end{array}$ & $\begin{array}{l}10 \mathrm{am} \\
\text { (lux) }\end{array}$ & $\begin{array}{l}11 \mathrm{am} \\
\text { (lux) }\end{array}$ & $\begin{array}{l}12 \mathrm{pm} \\
\text { (lux) }\end{array}$ & $\begin{array}{l}1 \mathrm{pm} \\
\text { (lux) }\end{array}$ & $\begin{array}{l}2 \mathrm{pm} \\
\text { (lux) }\end{array}$ & $\begin{array}{l}3 \mathrm{pm} \\
\text { (lux) }\end{array}$ & $\begin{array}{l}4 \mathrm{pm} \\
\text { (lux) }\end{array}$ & $\begin{array}{l}5 \mathrm{pm} \\
\text { (lux) }\end{array}$ \\
\hline 1 & $32.24 \%$ & $10.87 \%$ & $7.82 \%$ & $3.16 \%$ & $2.86 \%$ & $2.83 \%$ & $2.04 \%$ & $1.69 \%$ & $1.49 \%$ \\
\hline 2 & $48.47 \%$ & $9.82 \%$ & $10.71 \%$ & $3.07 \%$ & $3.09 \%$ & $3.11 \%$ & $2.23 \%$ & $2.09 \%$ & $1.71 \%$ \\
\hline 3 & $7.90 \%$ & $5.12 \%$ & $2.84 \%$ & $1.82 \%$ & $1.66 \%$ & $1.20 \%$ & $1.09 \%$ & $0.81 \%$ & $0.65 \%$ \\
\hline 4 & $5.14 \%$ & $4.12 \%$ & $2.43 \%$ & $1.76 \%$ & $1.64 \%$ & $1.14 \%$ & $0.88 \%$ & $0.83 \%$ & $0.77 \%$ \\
\hline 5 & $3.89 \%$ & $2.01 \%$ & $1.77 \%$ & $1.07 \%$ & $0.82 \%$ & $0.76 \%$ & $0.35 \%$ & $0.46 \%$ & $0.38 \%$ \\
\hline 6 & $3.21 \%$ & $1.80 \%$ & $1.60 \%$ & $1.13 \%$ & $0.75 \%$ & $0.70 \%$ & $0.61 \%$ & $0.50 \%$ & $0.48 \%$ \\
\hline
\end{tabular}

illuminance levels and affect negatively the occupants' health causing exhausting conditions.

\subsubsection{Daylight Factor}

DF (daylight factors) for the daylight factor calculations, 6 grids in a patient room was used. The results show that the DF values in the patient rooms are above the recommended minimum DF in hospitals, $1 \%$, by Thomas (1996) as shown in Table 3.

\subsection{Solution Systems}

Based on physical environmental measurement and lab test for this research, the dynamic louvers with reflective surfaces and diffuse daylight technique is used as the control strategies of solar irradiation and shading systems for enhanced daylight control. This option of solutions will be tested to be used in pediatric department in JUH depending on previous studies and case study building which used this strategy.

The vertical sun-shading devices will be provided in the east patients' rooms to avoid the excessive glare caused by direct sunshine from window at the morning. Diffuse skylight reflected upward from horizontal louvers and diffuse skylight reflected downward from ceiling will be provided to transfer the sunlight to the depth of room. This daylight control system is chosen based on the analysis for previous cases and study the potential of this system as mentioned in literature review early in this study.

One of the key goals of daylight control systems is to improve daylight autonomy by maximizing the daylight level at the rear of the space, which increases the time where interior zones of the building are above a target minimum illuminance level. In order to achieve a maximum amount of daylight autonomy, it is also necessary to minimize glare by lowering excessive lighting levels near the window. Doing so eliminates the need for occupants near the windows to close blinds or other operable shading systems [14], which in turn lowers lighting levels deeper in the space. Typical criteria used for evaluating a daylight control system comprise of shading capability, glare protection, unobstructed view toward the outside, light guidance into the depth of the room, homogeneous illumination/light distribution, energy-saving potential, tracking requirements, dynamic adjustment capability for transient solar condition, and the availability of the system as a product [15-21].

The potential energy savings due to the dynamic louvers with lighting control rely substantially on lighting and cooling loads. The reduction of these loads is roughly proportional to the degree of the louvers openness and its relation to solar position [22].

The vertical louvers work to decrease the direct sunlight at the rear of the room in the morning, and the horizontal louvers will reflect the direct sunlight to the diffuse skylight which is located on the ceiling to increase the illuminance deeper in room. Experimental tests are conducted by using scale model and Heliodon simulator in day light test lab at Jordan University.

The main intention here is to find out the best louvers control system (shape, size and location) with diffuses (location and size) which can be achieved the comfortable environment for patient rooms. These three different tools (vertical louvers, horizontal louvers and diffuses) worked beside each other to reach illuminance levels which are 
recommended by CIBSE.

\section{Lab test:}

Test model made in the same dimensions of the reality room in scale $1 / 20$. The lux meter tool is used to measure the illuminance level in each point. Heliodon simulator is set in the Amman latitude, in April month and for mention hours. See Fig. 4.

\section{(1) Case 1}

Using vertical wood louvers $(20 \mathrm{~cm}$ in width, $2 \mathrm{~cm}$ in thickness, $2 \mathrm{~m}$ in height and the distance between each one is $35 \mathrm{~cm}$ ) in the morning from 9 am until 12 pm at points 1, 2, 3 and 4 where the average illuminance level exceeds the recommended values. The total number of lovers for each window is 6 pieces.

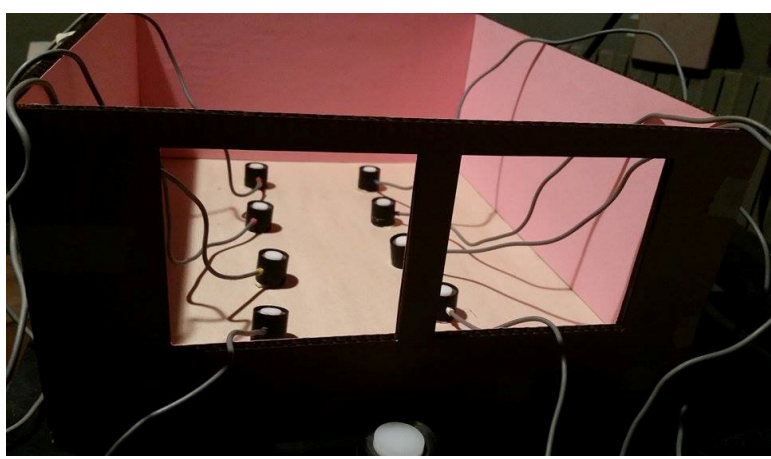

The results of illuminance level are approximately around the recommended values at points 1-4 and less than recommended value in points 5 and 6 as shown in Table 4.

(2) Case 2

Using horizontal louvers (reflected surfaces $2 \mathrm{~m}$ in width, $1 \mathrm{~cm}$ in thickness, $30 \mathrm{~m}$ in depth and the distance between each one was $50 \mathrm{~cm}$ ) in the afternoon in the same points. The total number of louvers for each window is 4 pieces. In the same case using rectangular diffused between points 4 and 6 , another one between 3 and 5 . The size of each one is $(1.5 \times 1.2) \mathrm{m}$. The result of illuminance level is between 100 lux and 300 lux, so it reaches the recommended value. See Table 5.

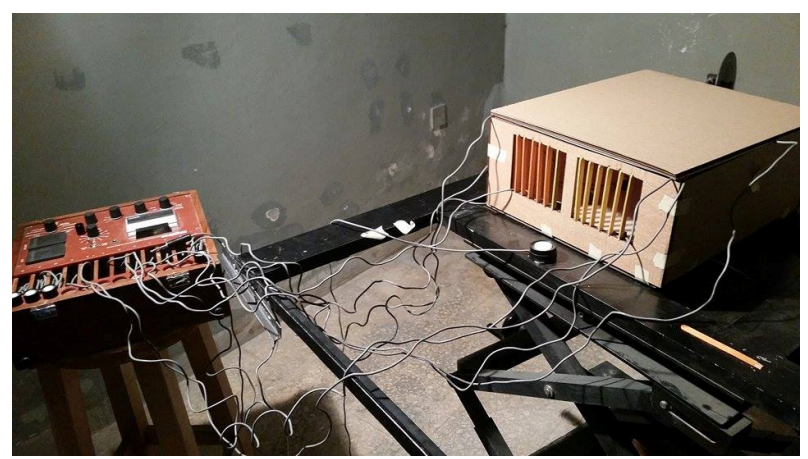

Fig. 4 Lab test model, 2015, the researchers.

Table 4 Lab test results of illuminance level at morning.

\begin{tabular}{lllllll}
\hline Point & 1 & 2 & 3 & 4 & 5 & 6 \\
\hline Illuminance level & 211 & 215 & 170 & 164 & 78 & 73 \\
\hline
\end{tabular}
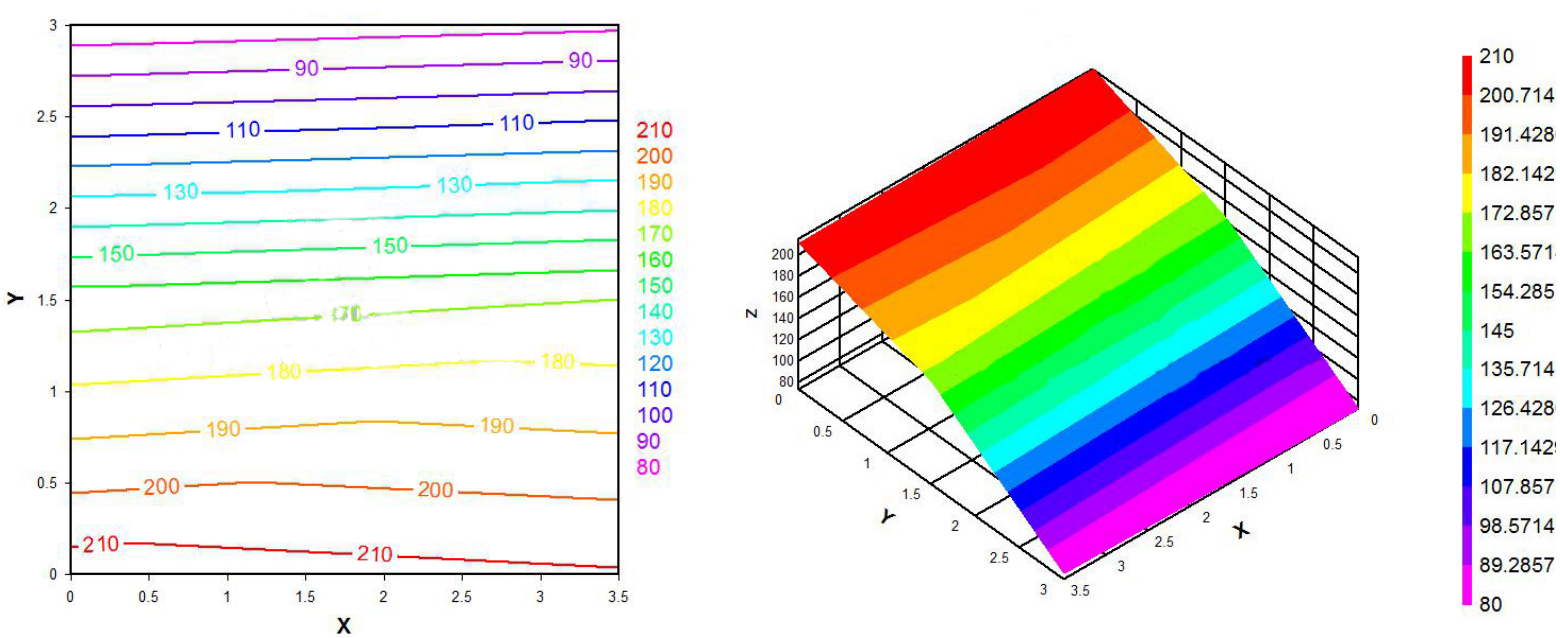

Fig. 5 Case 1 result using D-plot, 2015, the researchers. 
Table 5 Lab test results of illuminance level at afternoon.

\begin{tabular}{lllllll}
\hline Point & 1 & 2 & 3 & 4 & 5 & 6 \\
\hline Illuminance level & 260 & 262 & 245 & 225 & 211 & 207 \\
\hline
\end{tabular}

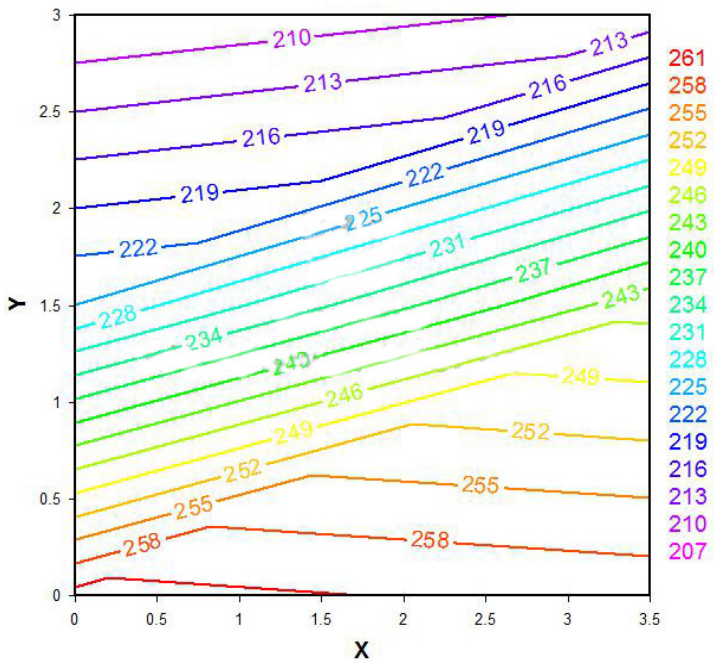

Fig. 6 Case 2 result using D-plot, 2015, the researchers.

\section{Conclusions}

This study has evaluated and analyzed the indoor daylight quality at Pediatrics Ward in JUH. These are carried out by conducting a multi-method approach including on-site measurements, and lap test to develop a framework for lighting design in Pediatrics Ward.

The study found that the indoor daylight performance in terms of illuminance, luminance level, and daylight factor in east patients' rooms are higher than the recommended values by CIBSE in the area nearest to glass window at the morning and less the recommended values in the depth of the room at afternoon. This means that the patients in the east facing rooms exposed to visual discomfort like glare.

According to experimental tests, the day light control strategy which consists of the vertical louver, horizontal louver with reflected surface and sky light diffuse is successful. This strategy solves the problem and gives optimized indoor daylight performance in terms of illuminance which reaches the recommended values by CIBSE. This strategy can be applicable in east patients' rooms to avoid the excessive glare and

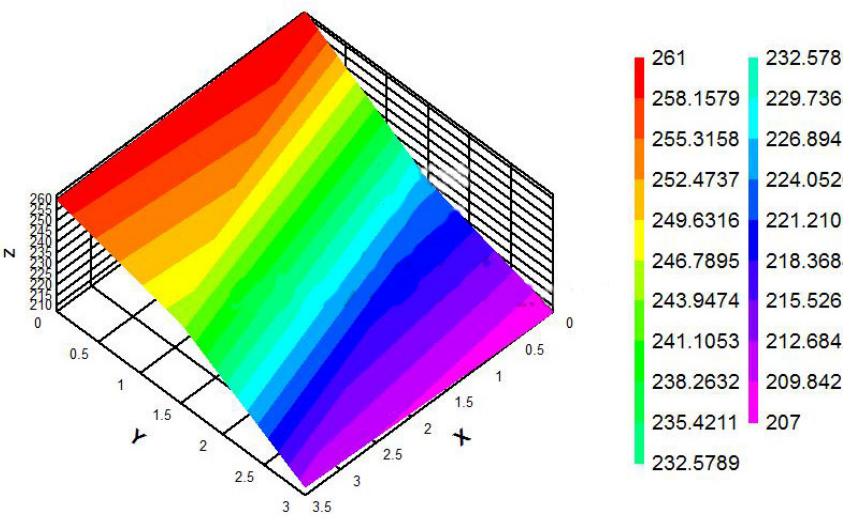

to provide an effective visual comfort environment for patients and staffs.

Finally, the physical environment of the hospital has a significant impact on health and productivity; lighting in hospitals is linked to patients' health. Accesses to daylight can positively affect human performance; good day lighting contributes immensely to the psychological and physical well-being of patients. Enhancing patient health should be integrated with all aspects of the design of hospital interiors and exteriors.

\section{Recommendations}

This study is to encourage the consideration to daylight quality in the health care building and recommends making another research in this filed in Jordan.

\section{Acknowledgments}

The authors would like to thank the Department of Architecture at Jordan University facilitating this study specially Prof. Riziq Hammad.

Special thanks go to the administration of Jordan University Hospital for being very cooperative during the on-site measurements. 


\section{References}

[1] Alzoubi, H. H., and Al-Rqaibat, S. M. The Effect of Hospital Design on Indoor Daylight Quality in Children Section. In King Abdullah University Hospital, Jordan, College of Architecture and Design, Jordan University of Science and Technology, Irbid 22110, Jordan.

[2] Ulrich, R. S., Zimring, C., Zhu, X., Du Bose, J., Seo, H., and Choi, Y. 2008. "A Review of the Research Literature on Evidence-Based Healthcare Design (Part I)." Health Environments Research and Design 1 (3): 61-125.

[3] Alimoglu, M. K., and Donmez, L. 2005. "Daylight Exposure and the Other Predictors of Burnout among Nurses in a University Hospital." International Journal of Nursing Studies 42 (5): 549-55.

[4] Ulrich, R. S., Zimring, C., Joseph, A., Quan, X., and Choudhary, R. 2004. The Role of the Physical Environment in the Hospital of the 21st Century: A Once-in-a-Lifetime Opportunity. Concord, CA: The Center for Health Design.

[5] Dickerman, K., and Barach, P. 2005. "Designing the Built Environment for a Culture and System of Patient Safety-A Conceptual, New Design Process." In Advances in Patient Safety: New Directions and Alternative Approaches. Culture and Redesign, edited by Henriksen, B. S. K., Battles, J. B., and Keyes, M. A. AHRQ Publication No. 08-0034-2 (Vol. 2). Rockville, MD: Agency for Healthcare Research and Quality.

[6] Per-Anders Enkvist, T. N., and Rosander, J. 2007. “A Cost Curve For Greenhouse Gas Reduction.” In A Global Study of Size and Cost of Measures to Reduce Greenhouse Gas Emissions Yields Important Insights for Businesses and Policy Makers. M. Company: Stockholm.

[7] Phelps, A., Horman, M., Barr, M., Brower, J., Riley, D., Vanegas, J., and Pearce, A. 2006. "Bridging the Physics of Building with the Physiology of Health Care: Greening Healthcare Facilities.” Journal of Green Building 1 (2): 164-76.

[8] Stichler, J. F. 2009. "Code Green: A New Design Imperative for Healthcare Facilities." Journal of Nursing Administration 39 (2): 51-4.

[9] Verderber, S., Fauerbach, J., and Walter, B. 2008. "On the Value of Environmental Stewardship and Sustainability in Health Administration Education." Journal of Health Administration Education 25 (3): 191-211.

[10] Ficca, S. A., Chyun, Y. D., Ebrahimi, M., Kutlak, F., and Memarzadeh, F. 2000. "Activities of the National Institutes of Health Relating to Energy Efficiency and Pollution Prevention." Environ Health Perspect 108 (Suppl 6): 939-44.

[11] Garrett, L., Chowdhury, A. M. R., and Pablos-Méndez, A. 2009. “All for Universal Health Coverage.” Lancet 374
(9697): 1294-9.

[12] Bataineh, A., and Ali, H. H. "A Study of Thermal Performance Analysis of Low-Income Housing in Jordan: Case of SOS Buildings." Department of Architecture, College of Architecture and Design, Jordan University of Science and Technology, Irbid-Jordan.

[13] Canziani, R., Peron, F., and Rossi, G. 2004. "Daylight and Energy Performances of a New Type of Light Pipe." Energy and Buildings 36 (11): 1163-76.

[14] Littlefair, P. J., Aizlewood, M. E., and Birtles, A. B. 1994. "The Performance of Use Day Lighting Systems." Renew Energy 5 (5): 920-34.

[15] Colaco, S. G., Kurian, C. P., George, V. I., and Colaco, A. M. 2008. "Prospective Techniques of Effective Daylight Harvesting in Commercial Buildings by Employing Window Glazing, Dynamic Shading Devices and Dimming Control and a Literature Review." Building Simulation 1 (4): 279-89.

[16] Hocheng, H., Huang, T. Y., Chou, T. H., and Yang, W. H. 2010. "A Brighter Place: Overview of Microstructured Sunlight Guide." Journal of Achievements of Materials and Manufacturing Engineering 43 (1): 409-17.

[17] Huang, T. Y., Hocheng, H., Chou, T. H., and Yang, W. H. 2013. "Bring Free Light to Buildings: Overview of Daylighting System." In Materials and Processes for Energy: Communicating Current Research and Technological Developments, edited by Mendez-Vilas A. Formatex Research Center.

[18] Kischkoweit-Lopin, M. 2002. "An Overview of Daylighting Systems.” Solar Energy 73 (2): 77-82.

[19] Klammt, S., Müller, H., and Neyer, A. 2009. "Advanced Daylighting by Micro Structured Components." In Proceedings of the Global Lighting Design Conference, 2-3.

[20] Ruck, N., Aschehoug, O., Aydinli, S., Christoffersen, J., Courret, G., and Edmonds, I. 2001. Daylight in Buildings. A Source Book on Daylighting Systems and Components. A report of IEA SHC Task 21/ ECBCS Annex 29, July 2000.

[21] Ullah, I., and Shin, S. 2013. "Uniformly Illuminated Efficient Daylighting System.” Smart Grid Renew Energy 4 (2): 161-6.

[22] Hammada, F., and Abu-Hijlehb, B. 2010. "The Energy Savings Potential of Using Dynamic External Louvers Nin an Office Building." Energy and Buildings 42 (10): 1888-95.

[23] Phiri, M. 2003. One Patient One Room-Theory \& Practice: An Evaluation of the Leeds Nuffield Hospital.

[24] Roseman, C., and Booker, J. M. 1995. "Workload and Environmental Factors in Hospital Medication Errors." Nursing Research 44 (4): 226-30. 